\title{
“SER" UM/A PROFESSOR/A DISSIDENTE: entre a vida que se constrói de forma contingente e a ficção representativa
}

\author{
Silas Veloso de Paula Silva \\ Isabella Nara Costa Alves
}

\begin{abstract}
Resumo
Este ensaio busca provocar reflexões sobre identidades docentes, discutindo as im(possibilidades) de qualquer fechamento e sutura dos sujeitos que as incorporam. Aponta-se a representação hegemônica do/a profissional docente como uma ficção representativa que se modifica ou se conserva de acordo com as disputas pelas demandas educativas. A partir de discussões teóricas sobre identidade, sujeito e performance, e de experiências vividas pelos autores/as e/ou por docentes mencionados/as aqui como "dissidentes", reitera-se a relevância do olhar para as diversas posições desses sujeitos humanos e profissionais a partir da concepção de que não se nasce professor/a torna-se um/uma. O trabalho é fruto de uma pesquisa qualitativa, de caráter exploratório, a partir de uma perspectiva orientada aos problemas expostos (problem driven researche), conclui-se situando a regulação das identidades e performances docentes diante dos discursos hegemônicos de normatização e as (im)possibilidades de superar tais restrições através de corpos e experiências dissidentes no campo da educação.
\end{abstract}

Palavras-chave: docência; dissidência; ficção.

“BEING” A DISSIDENT TEACHER: between life that is built contingently and representative fiction

\begin{abstract}
This essay seeks to provoke reflections on teaching identities, discussing the (im)possibilities of any closure and suture of the subjects who incorporate them. The hegemonic representation of the teaching professional is pointed out as a representative fiction that is modified or preserved according to the disputes over educational demands. Based on theoretical discussions about identity, subject and performance, and experiences lived by the authors and/or by teachers that we mention here as "dissidents", the relevance of looking at the different positions of these human and professional subjects is reiterated, from the conception that one is not born a teacher becomes one. The work is the result of a qualitative research, with an exploratory character, from a perspective oriented to the exposed problems (problem driven researche), concludes by placing the regulation of teaching identities and performances in face of the hegemonic discourses of normatization and the (im)possibilities to overcome such restrictions through dissident bodies and experiences in the field of education.
\end{abstract}

Keywords: teaching; dissent; fiction.

"SER" UN/A MAESTRO/A DISIDENTE: entre la vida que se construye de manera contingente y la ficción representativa

Resumen

Este ensayo busca provocar reflexiones sobre las identidades de enseñanza, discutiendo las im (posibilidades) de cualquier cierre y sutura de los sujetos que las incorporan. La representación hegemónica del profesional docente se señala como una ficción representativa que se modifica o preserva de acuerdo con las disputas sobre las demandas educativas. Basado en discusiones teóricas sobre identidad, materia y desempeño, y experiencias vividas por los autores y/o maestros que mencionamos aquí como "disidentes", 
se reitera la relevancia de mirar las diferentes posiciones de estas materias humanas y profesionales. Desde la concepción de que uno no nace, un maestro se convierte en uno. El trabajo es el resultado de una investigación cualitativa, con un carácter exploratorio, desde una perspectiva orientada a los problemas expuestos (investigación orientada a problemas), concluye colocando la regulación de las identidades y actuaciones docentes frente a los discursos hegemónicos de normatización y las (im) posibilidades de superar tales restricciones a través de cuerpos disidentes y experiencias en el campo de la educación.

Palabras clave: docência; dissidência; ficção.

INTRODUÇÃO

"Nunca é alto o preço a pagar pelo privilégio de pertencer a si mesmo."

(Friedrich Nietzsche)

Este texto nasce de um movimento re(existencial), - talvez, semelhante ao que Hall (2006) chamou de "crise de identidade" - que nos provocou a refletir de forma particular sobre o campo discursivo da profissão docente: tal movimento, foi o de repensar nossa trajetória enquanto educadoras, ao mesmo tempo em que buscávamos compreender o que Laclau e Mouffe (2015) concebiam enquanto sujeito. Passamos a refletir sobre a fantasia - no sentido lacaniano - cruel contida nos símbolos, significados, e expectativas criadas sob este ofício, guiados/as pelas (in)certezas das seguintes proposições: não se nasce professor/a, torna-se um $/ \mathrm{a}^{1}$ e não existe uma realidade educacional suturada que detenha o poder ou o direito de determinar o que é "ser" professor/a.

Existe um discurso hegemônico de romantização e personificação excessiva do "ser" professor/a, que ignora o fato de ninguém se tornar um profissional da educação de um dia para noite, ou em um passe de mágica, a partir do momento em que se pega um diploma e busca-se uma vaga de emprego, para que então se possa carregar o status/fardo ${ }^{2}$ de educador/a. Dentro desse discurso, a condição de sermos, sobretudo, humanos/as é totalmente ignorada quando se é ou está se tornando um/uma professor/a. As diferentes posições de sujeitos também parecem não ser levadas em conta, através de uma ficção generalizada de que somos: capazes de curar feridas emocionais de alunos/as; corrigir provas e atividades e concluir páginas de livros didáticos em um curto espaço-tempo; salvar a vida de alunas/os com famílias "desestruturadas" e/ou envolvidos/as com drogas, problemas familiares e outros diversos; planejar e executar aulas, atualizar cadernetas; elaborar projetos educacionais e eventos escolares; e mais um milhão de "missões" impostas ao/à profissional que quanto mais se submete ao papel de herói/heroína das gerações, mas é contraditoriamente aplaudido/a.

Dizemos contraditoriamente, pois o reconhecimento da profissão, pelo menos no Brasil, parece nunca ter existido. Isso se mostra através dos salários e dos insatisfatórios valores de horaaula, onde em 2019, segundo a pesquisa TALIS, da OCDE³ ${ }^{3}$, recebíamos os piores em um universo de 48 países. Mais que isso, existe toda uma concepção moral e ética baseada em racionalismos falidos que exige do/a professor/a uma posição de integridade homogênea e hegemônica, para

\footnotetext{
${ }^{1}$ Parafraseando Beauvoir (1967), "não se nasce mulher, torna-se".

${ }^{2}$ Esse status/fardo se dá não de uma forma geral para todos os sujeitos docentes, depende de cada trajetória, de cada contexto de ensino e aprendizagem. Mas no geral, a profissão docente sempre foi e tem sido atribuída a uma naturalização de sobrecarga nas atividades, ressentimento e sofrimento.

${ }^{3}$ Disponível em: https://oglobo.globo.com/sociedade/professores-brasileiros-tem-os-piores-salarios-afirma-ocdeem-levantamento-feito-em-48-paises-23752804. Acesso em: 11/07/2020.
} 
além dos limites físicos dos espaços educacionais onde atuam, fazendo-o/a ter medo de pensar e viver de acordo com seus próprios valores; atropelando os seus próprios processos humanos, muitas vezes, atravessados por depressões, e crises de pânico e ansiedade: "produza ou será morto/a", eles/as gritam ${ }^{4}$. Além disso, nos dias atuais, enfrentamos diversos ataques relacionados ao ofício de ensinar, a exemplo citamos os discursos presentes no Projeto Escola Sem Partido ${ }^{5}$ no pânico moral difundido através da famigerada "ideologia de gênero" que buscam politicamente, adequar a profissão docente às moralidades e concepções educacionais de grupos específicos (neoconservadores e neo-liberais). Na maioria das vezes, tais racionalismos são calcados em lógicas sociais ${ }^{7}$ que agrupam práticas e regimes sociais brancos, cis-gêneros, heterossexuais, e classistas.

$\mathrm{Na}$ contemporaneidade, "professor/a" ainda remete a uma ideia de sujeito fissurado, de existência "racional", transparente, homogênea com limitações e restrições, frutos de falsos moralismos que por meio de discursos como o de angelicalização da docência, estabelece restrições e limitações sob as formas que cada sujeito/professor/a vive e constrói sua própria vida. Dentro dessa lógica de sujeito profissional, um/a professor/a, fora de seu exercício docente, por exemplo, não pode: beber, fumar, fazer sexo, falar palavrão, adoecer, chorar, surtar, se apaixonar por qualquer pessoa, usar determinadas roupas, frequentar determinados tipos de lugares, ter redes sociais e postar determinados conteúdos. Ele/a precisa, representar a "moral e os bons costumes", dentro de lógicas sociais que são reiteradas por sua vez, pela identificação dos sujeitos com fantasias sociais. - No sentido de Glynos e Howarth (2007) -. Citamos como uma dessas fantasias a imagem do/a professor/a como um ser iluminado que carrega em suas práticas profissionais a salvação de uma sociedade violenta, auto-destrutiva, e estratificada

Fantasia é compreendida como uma narrativa que encobre ou anula a falta do sujeito ao fornecer uma imagem de plenitude, completude ou harmonia, por um lado, enquanto conjura ameaças e obstáculos à sua realização por outro. Quando instalada com sucesso, uma narrativa fantasmática captura o sujeito - através do gozo que ela produz - para uma determinada prática ou ordem, ou uma prática em ordem prometida, conferindo assim uma identidade. (GLYNOS; HOWARTH, 2007, p. 130).

Seguindo as abordagens de Glynos e Howarth (2007), compreendemos que essas fantasias sociais, impõem à identidade docente o papel ou função de representar o horizonte, tão requisitado diante da falta constitutiva do sujeito, através de um gozo que não se circunscreve apenas entre os sujeitos professores, mas nas expectativas de pais, mães, familiares, religiosos e políticos, que tratam a educação como a marionete de seus jogos discursivos e de re(afirmação) de suas lógicas sociais. Ao escrever esse texto, pretendemos apontar a dimensão horrorifica da fantasia sob as práticas docentes, deslocando o olhar sob esses/as profissionais de uma estrutura educacional e sistêmica ao mundo

\footnotetext{
${ }^{4}$ https://www.brasildefatopr.com.br/2019/10/15/suicidio-de-professores-no-parana-aumenta-15-vezes-em-cincoanos. Acesso em: 17/06/2020.

${ }^{5}$ De acordo com Silva, Alves e Vidal (2020), o Projeto Escola Sem Partido, também conhecido como "lei da mordaça" é um movimento reacionário que propõe a retirada de temas como política, religião, gênero e sexualidade nas escolas, acusando docentes de doutrinação ideológica.

6 "Ideologia de gênero" é um sintagma conservador-reacionário aos estudos e pesquisas em gênero e sexualidade, sobretudo nos espaços educativos, regido por uma lógica fantasmática de "pânico moral" de docentes-militantes que iriam incentivar a homossexualidade e a "atividade sexual precoce" em crianças nas escolas (SILVA, ALVES e VIDAL, 2020).

${ }^{7}$ No sentido de Glynos e Howarth (2018).
} 
da vida (Lebenswelt), rompendo com as tradições e metanarrativas acerca do que é "ser professor/a", oriundas dos parâmetros universalistas, modernos e dicotômicos.

Quando optamos por deslocar o "ser-professor/a" de uma perspectiva estrutural, universal e moderna que põe a prática docente como uma peça no jogo de disputas pelas demandas políticoeducacionais, estamos nos opondo às análises engessadas, universalizantes, polarizadas, messiânicas, voluntaristas e totalizantes, que a partir de sua metafísica da presença ${ }^{8}$ negligenciam o lugar do sujeito no exercício "de ser ou tornar-se professor/a"; onde tal sujeito diante de uma 'vida' contingente não é, e não pode ser professor/a 24 horas por dia, tão pouco por toda uma vida. É neste sentido que lançamos as questões que se seguem: Quem é o ser humano que existe por trás da condição robótica e fictícia que representa o/ professor/a contemporâneo/a? E qual a relevância de trabalhos que se dediquem a análise de tal condição?

Tais indagações, nos remetem aos clássicos manuais políticos/educacionais que estudamos durante a licenciatura no decorrer de nossas formações em ciências sociais e pedagogia, que pareciam exigir e/ou sugerir ao/à professor/a em formação: condutas, práticas e apreensões de valores essencialistas e hegemônicos, ao mesmo tempo em que pouco se eram demonstrados, discutidos ou trabalhados o cuidado com o/a profissional docente em outros âmbitos, como por exemplo, o âmbito emocional e psicológico. Em contrapartida, em nossa experiência, foi e é muito comum, ainda que de forma indireta, aprendermos sobre um ethos profissional permeado de restrições e imposições morais e éticas que, quando vivenciados nos ambientes educacionais, se relacionam diretamente com uma homogeneidade nos: modos de falar; de se vestir; lugares a serem frequentados; hábitos de vida; modos de se relacionar; posicionamentos políticos; restrições estéticas e corporais; na concepção e vivência do gênero e orientação sexual, na concepção de família; posicionamentos e vivências religiosas e etc.

Assim como para Laclau e Mouffe (2015) os sujeitos não podem ser a origem das relações sociais, refletimos nesta direção que os/as professores/as não deveriam ser a origem ou a ferramenta que faz a educação mercadológica funcionar e para além, que os aspectos particulares dos processos humanos, inerentes a cada sujeito docente, não devem ser suprimidos ou re(oprimidos) por essas lógicas sociais que operam na hegemonia política, social e educacional. Em outras palavras: Estamos discutindo o aspecto humano (não humanista) do processo que é "ser" e/ou "tornar-se" de forma contínua e contingente um/a profissional docente.

Nesse processo de vigiar e punir" que impõe a necessidade "de ser" um professor/a ideal, interrompendo, reprimindo e violentando outras esferas do mundo da vida, muitas vezes nos falta tempo para viver as "realidades" que apontam caminhos contrários ao adoecimento mental ${ }^{10} \mathrm{e}$ físico. São várias as experiências vividas por nós e por outros/as colegas, que nos mostram: quando o sujeito docente escolhe com suas próprias práticas denunciar a ficção de seu papel, é punido/a, seja como doutrinador/a, como louco/a; como irresponsável; como imaturo/a; insubordinado/a; anti-científico; ou como qualquer outra coisa distante do sujeito super-homem/mulher-maravilha que os discursos hegemônicos no campo educacional estabelecem.

A relevância deste ensaio configura-se como emergência em contraposição aos diversos discursos neo/conservadores empregados à performance docente desde o processo de "feminização" do magistério, marcada atualmente pelo paradoxo entre o imaginário messiânico atribuído à educadores/as e sua desvalorização e desumanização refletidas nas exaustivas jornadas

\footnotetext{
${ }^{8}$ No sentido de Jacques Derrida.

${ }^{9}$ No sentido de Foucault (1987).

${ }^{10}$ Estudos apontam a incidência da Síndrome de Burnout entre docentes - que tem como principal característica o stress ocasionado pelo ambiente de trabalho, além de outras psicopatologias (LEVY, SOBRINHO e SOUZA, 2009).
} 
de trabalho e constantes ataques à educação pública e às universidades, gerando sentimentos de perseguição e frustração devido ao papel "doutrinador" em sala de aula. Mais que isso, é de nosso interesse pensar o/a professor/a, para além da sala de aula, no "mundo da vida" (Lebenswelt), refletindo e dando ênfase aos diversos discursos e abordagens que suprimem o aspecto humano desses sujeitos, pois, ao mesmo tempo em que essas identidades profissionais se constituem por meio de uma relação interdiscursiva nos espaços educacionais, os sujeitos têm uma vida fora destes. Essa separação entre espaços de trabalho e mundo da vida não é uma mera abstração analítica nossa, se trata de uma abstração real de que os espaços de educação, sobretudo os formais, são significados a partir de uma externalidade do social, que também criticamos aqui. Tais reflexões fazem ecoar os diversos problemas que as concepções hegemônicas de performance docente trazem ao sujeito que é e/ou está se tornando professor/a, como por exemplo o adoecimento mental e em casos extremos, o suicídio.

\section{DELINEAMENTO METODOLÓGICO: NARRATIVAS QUE PARTEM DE DOCÊNCIAS DISSIDENTES}

Diante destes desafios, nossa proposta principal - a partir de uma perspectiva orientada aos problemas expostos (problem driven research) - é refletir sobre os discursos que atravessam a performance docente, fazendo uma relação entre as identidades contingentes e as representações sócio-políticas presentes nesses discursos, que reverberam nos corpos dissidentes e suas resistências. Segundo Oliveira, G.; Oliveira, A. e Mesquita (2013) a escolha de uma pesquisa orientada ao problema certamente, não deve implicar numa ausência de reflexões teóricas ou de rigor e seriedade metodológica, mas, numa elaboração em que a linha que conduz o trabalho seja o enfrentamento do problema proposto, em que a teoria e a metodologia providenciem recursos para enriquecer e aprofundar a compreensão do problema analisado. A perspectiva adotada se dá pelo nosso posicionamento contrário a um viés positivista, que segundo Glynos e Howarth (2018), "têm fortalecido a divisão entre questões de fato e explicação e questões de crítica e avaliação normativa, por meio da ênfase da neutralidade axiológica na pesquisa científica social". (GLYNOS; HOWARTH, 2018, p. 53). Segundo os autores, uma abordagem que tem como tarefa uma explicação crítica, é baseada em uma articulação de uma ontologia social que enfatiza a contingência radical e a incompletude estrutural de todos os sistemas de relações sociais. Neste sentido, "a importância da ontologia não é apenas sobre quais tipos de coisas existem, mas que elas existem e como elas existem". (GLYNOS; HOWARTH, 2018, p. 56). Sendo de importância maior: a contingência a precariedade e a historicidade dos sujeitos.

Como escudos teóricos, utilizaremos os Estudos Culturais através das perspectivas de Stuart Hall (2004) assim como, a Teoria política do Discurso de Laclau e Mouffe (2015) e discussões pós-estruturalistas em torno da noção de sujeito; bem como o conceito de performance advindo da teoria queer de Judith Butler (2003); como ferramentas teórico-metodológicas que nos habilitam analisar as representações acerca dos sujeitos docentes em meio aos contextos recentes, atravessados pelas empreitadas da "barbárie da educação" político-jurídico-midiático de 2016 - que destituiu da presidência Dilma Rousseff, a primeira mulher eleita democraticamente como presidenta da república - até o advento do reacionarismo

\footnotetext{
${ }^{11}$ Para saber mais, ver "A educação contra a barbárie: por escolas democráticas e pela liberdade de ensinar" de Fernando Cássio (org., 2019).
} 
bolsonarista em meio à pandemia de COVID-19 ${ }^{12}$. Entendemos como movimento Bolsonarista: as articulações, grupos e organizações que apoiam o governo reacionário de Jair Bolsonaro (20192022) e suas propostas "políticas" para o Brasil. Para além de diversas medidas articuladas às pautas neo-conservadoras e neoliberais, o governo Bolsonaro tem representado negligência e descaso frente às medidas de prevenção e combate à pandemia causada pelo COVID-2019, que vem se espalhando pelo mundo e provocando muitas mortes, sendo o Brasil, até o presente momento, o segundo país com mais mortes em termos absolutos (BBC NEWS, 2020). Algumas dessas medidas que julgamos representar descaso e negligência são por exemplo: a banalização dos perigos acerca da doença, a propagação de não seriedade frente ao isolamento social e a paralisação de atividades que possivelmente poderiam espalhar o vírus e multiplicar o número de casos; assim como o estímulo de medicamentos como a cloroquina, em contrariedade aos estudos científicos e médicos.

Ainda sobre os aspectos metodológicos, e mais especificamente sobre quando nos colocamos em primeira(s) pessoa(s) em alguns trechos do trabalho, nos baseamos a partir das considerações de Oliveira (2018), que calcado em uma perspectiva pós-estruturalista, reflexiona sobre o próprio conhecimento científico enquanto um discurso e tudo o que concebemos do social, como ontologicamente político. A perspectiva pós-estruturalista insiste - e esse é um ponto que a diferencia das abordagens construcionistas clássicas - em levar às últimas consequências o reconhecimento de que o sujeito e o trabalho de pesquisa não existem em um plano ontologicamente e/ou epistemologicamente separado da realidade pesquisada. (OLIVEIRA, G., 2018, p. 185).

Este trabalho, portanto, é fruto de uma pesquisa qualitativa em andamento, de caráter exploratório, uma vez que construímos reflexões teóricas quanto aos problemas apontados pelos/as autores/as em articulação com as situações vividas em nossa formação e exercício docente: "Nuestras vidas son verdadeiras epistemologias" (RÍOS, 2004). Nossas histórias de vida são mais que inspirações e discursos sobre si, são incontestáveis ferramentas metodológicas. Por isso trazemos também fragmentos da história de vida de um professor, para exemplificar o que chamamos aqui de: professores/as dissidentes.

Tais corpos humanos e profissionais representam o Outro desse simulacro e arquétipo de identidade docente hegemônica. Podemos citar como exemplo de professores/as dissidentes: aqueles/as que se posicionam frente às injustiças sociais; os/as professores/as que com seus corpos e vivências se contrapõem à moralidade e a falsa benevolência cristã/hegemônica; os corpos nãobinários e não-heterossexuais que ocupam ou almejam exercer a prática docente; aos/às professores negros/negras que enfrentam - ainda que de forma inconsciente - o racismo educacional; às professoras cis e trans que historicamente exercem suas profissões sob condições desumanas, machistas e misóginas; aos/às educadores/as populares e de espaços não-formais; professores/as anti-proibicionistas, corpos trans e feministas. Este texto é sem dúvidas direcionado a todos/as os/as profissionais docentes, que um dia se sentiram incapazes de exercer o seu ofício por serem loucos/as, vadias, desvirtuosos/as, insubordinados/as, perigosos/as, sujos/as, marginais e rebeldes.

\footnotetext{
${ }^{12}$ Segundo o site do ministério da saúde, “em dezembro de 2019, houve a transmissão de um novo coronavírus (SARSCoV-2), o qual foi identificado em Wuhan na China e causou a COVID-19, sendo em seguida disseminada e transmitida pessoa a pessoa. A COVID-19 é uma doença causada pelo coronavírus, denominado SARS-CoV-2, que apresenta um espectro clínico variando de infecções assintomáticas a quadros graves. De acordo com a Organização Mundial de Saúde, a maioria (cerca de 80\%) dos pacientes com COVID-19 podem ser assintomáticos ou oligossintomáticos (poucos sintomas), e aproximadamente $20 \%$ dos casos detectados requer atendimento hospitalar por apresentarem dificuldade respiratória, dos quais aproximadamente $5 \%$ podem necessitar de suporte ventilatório."
} 
DOI: $10.12957 /$ teias.2021.53031

\section{DISCUSSÕES TEÓRICAS: IM(POSSIBILIDADES) DA PERFORMANCE DOCENTE EM CRISE}

Os jesuítas, na narrativa hegemônica da história educacional do Brasil, são atribuídos de modo histórico e político como os primeiros professores (no masculino, uma vez que eram todos homens) das terras tupiniquins, em detrimento dos saberes epistêmicos da riqueza e da diversidade dos povos originários. A partir da década de 1550, impunham, com pretensões coloniais, o Ratio studiorum: o currículo e o código pedagógico dos jesuítas da época que pretendia a plena submissão ao serviço de Deus e ao serviço d'El-Rei.

A partir de uma simples construção genealógica de como se construiu a ideia de docência no Brasil, percebemos tal construção intimamente relacionada com a visão hegemônica do atual imaginário social sobre o magistério, uma vez que as regras de comportamento deveriam ser exercidas por todos (PAIVA, 2000). Naquela época, além do cânone catequizador e elitista presente nas instituições educacionais, o professor era uma figura de grande prestígio pelas suas atribuições como autoridade máxima na reprodução desse corolário conservador, sendo inclusive o termo "aluno" (utilizado até os dias de hoje) etimologicamente representativo de um sujeito sem luz.

Conforme Paiva (2000), não havia a ideia de divisão entre teoria e prática: os interesses de vida e as práticas cotidianas deveriam ser consentâneos, implementando culturalmente o "formalismo pedagógico" - semelhante a um formalismo cultural. A vida extra muros era vista como pecados, frequentemente pecados da carne: jogos proibidos, vícios, espetáculos, teatros, maus livros, más companhias.

Décadas se passaram - os jesuítas são expulsos do Brasil pelo Marquês de Pombal - e inúmeras reformas educacionais se estabelecem, como as Escolas Normais e sua consolidação no final do século XIX, em que o caráter classista e capitalista perdura e se retroalimenta, mas quem começa a ocupar o magistério são as mulheres - brancas e de classe média - uma vez que os homens são requisitados aos cargos de esfera pública, processo este conhecido como "feminização da educação": do mestre-escola para a professora. De acordo com Villela (2000), ainda que a formação profissional tenha sido possibilitada estrategicamente pela luta destas mulheres à entrada do mundo do trabalho através da fuga de um casamento arranjado, a docência se configurava como o "cuidar" e "educar" de crianças, atribuições associadas como "femininas" pelo essencialismo biológico. A associação entre a feminização e a docência tem como consequência a desvalorização do magistério, herança colonial e patriarcal que se perpetua até os dias atuais, assim como o processo cartesiano de dicotomia corpo-mente atravessados pelo discurso moralista e também capitalista, uma vez que o magistério cada vez mais atendia às classes sociais de baixa renda através da ampliação da rede escolar. Esta associação também reverbera nos discursos ambíguos do perfil da professora, em que

[...] ao substituir a mãe, esperava-se que a preceptora assumisse uma conduta materna, ou seja "assexuada", "respeitável", "pura". Contraditoriamente, por ser livre, solteira e desempenhar um trabalho assalariado representava uma constante ameaça aos valores e à estrutura familiar. Não é por acaso que na literatura do período existem tantas associações da preceptora, como mulher que busca sua independência, às figuras da louca e da prostituta, vistas também, como seres fronteiriços (VILLELA, 2000, p. 119).

Com o surgimento das Escolas Normais (responsáveis pela formação de professoras nos anos $1835 \mathrm{em}$ diante), os discursos higienistas e positivistas continuam a ser transmitidos através de regulamentos, diretórios, concursos, marcos legais, produção de conhecimento científico e 
matrizes curriculares, mesmo depois da sua extinção devido a fatores como o desprestígio da profissão docente. Os cursos de educação e licenciaturas continuam sendo ocupados majoritariamente por mulheres, experiência observada e vivenciada em nossa formação universitária. Não à toa, as diversas tarefas e demandas quanti-qualitativas atribuídas à professora (cuidadora, terapeuta, enfermeira, tia) são atribuídas também às mães: "guerreiras" que tudo suportam, trabalhadoras incansáveis, que (sobre)vivem em função de suas crias, em contraposição ao próprio processo de desumanização que admite sua importância, mas continua explorando-a como objeto de reprodução social ${ }^{13}$ mercado(lógico).

Através das epistemologias feministas e queer, dos Estudos Culturais, e da Teoria política do Discurso podemos problematizar a busca docente pela sua identidade profissional: o que é ser docente em um social sempre contingente? Porque escolhemos lecionar? Quais propostas biosociopolíticas estão atravessadas pelo "ser docente" e quando se é docente, que tempo sobra para sermos humanos/as e lidarmos com os diferentes papéis de sujeitos que somos?

A partir de Saviani (2007), em a História das idéias pedagógicas no Brasil, percebemos - fugindo das universalidades e totalizações de forma atenta e munidos/as por uma abordagem retrodutiva que as nossas formas de conceber "educação" têm sua gênese em momentos históricos coloniais, e que dentro dessas histórias (de modo contingente e em seu sentido hegemônico) sempre foram moduladas e "reformadas" diante das demandas mercadológicas, até os dias de hoje, onde assistimos, vivemos e nos contrapomos às diversas reformas educacionais alinhadas aos interesses do capitalismo neoliberal, a exemplo: a "reforma" do Ensino Médio no Brasil. ${ }^{14}$

Dentro de tais contextos, encontra-se o/a professor/a, figura importante para a consolidação de processos educacionais/sistêmicos. A identidade do/a professor/a, o arquétipo do que seria este sujeito ou a partir de Dubar (1997) os "atos de atribuição" 15 que constituem essa identidade, mudam paulatinamente ao longo do tempo e isso pode ser inferido através das próprias distinções de sujeito encontradas em Ciampa (1987); Mercer (1990) Dubar (1997); Bauman (2005); Laclau e Mouffe (2015).

Contudo, na contemporaneidade, os discursos conservadores - putrefatos da colonialidade e do moralismo religioso/hegemônico - pairam de modo renovado e articulado a outros discursos, a fim de uma contínua re(catequização) e regulação da prática docente e dos sujeitos que a constroem (dentro e fora dos espaços físicos educacionais).

Para dar sentido de forma ampla a tais reflexões, e argumentar a favor de uma prática docente sempre em desconstrução ${ }^{16}$; jamais fixa e acabada; nunca respondendo ou se relacionando com uma ideia de totalidade do social; que se volte a compreender as necessidades parciais do sujeito que existe por trás do "ser professor/a" em diferentes posições; e que considere, sobretudo a capacidade de aprender a aprender a "ser" professor/a; vamos começar refletindo sobre o que seria uma identidade docente ${ }^{17}$, - tema que segundo André (2009), tem despertado maior interesse de pesquisadores/as - para depois refletirmos sobre a noção de performance em Butler (2003) e Caetano (2016) e em seguida o sujeito e suas im(possibilidades) em Laclau e Mouffe (2015), em diálogo, com as identidades hegemônicas e lógicas sociais que os suprimem; a fim de desestruturar

\footnotetext{
${ }^{13}$ Para compreender sobre a teoria da reprodução social, ver Feminismo para os 99\% - um manifesto (ARRUZZA, BHATTACHARYA, FRASER, 2019).

14، "Reforma" que a nosso ver, instrumentaliza as práticas educativas aos modelos neoliberais de conceber educação.

${ }^{15}$ Corresponde a identidade para o outro.

${ }^{16}$ No sentido Derridiano.

${ }^{17}$ Para Faria e Souza (2011), a compreensão sobre a identidade docente pode trazer contribuições ao campo da formação e, em consequência, à educação escolar.
} 
qualquer tentativa de ficção e fixação ao conceber um/a profissional que ensina e que está sempre aprendendo a "ser" no "mundo da vida" (Lebenswelt).

\section{IDENTIDADE DOCENTE E FICÇÃO HEGEMÔNICA: POR QUE É PRECISO FALAR DE PERFORMANCE?}

O conceito de identidade como contingente, descentrada e mutável desenvolvido por Hall (2004) fornece formas de pensar o sujeito e suas estratégias de resistência por uma nova política da diferença, através de dispositivos de gênero, raça, sexualidade, nação, entre outros marcadores sociais. Evidenciando cultura como noções abrangentes de toda atividade simbólica, o autor rejeita sua equivalência à alta cultura, na argumentação do termo como representações e práticas que moldam qualquer sociedade, profundamente implicada em relações de poder. Nesta circunstância, os Estudos Culturais como teoria interdisciplinar, multidisciplinar ou contra-disciplinar, se preocupam com o papel do/a intelectual na mudança social e como a identidade do sujeito é articulada.

Mais que isso, Hall (2004), apresenta uma visão de identidade que é pertinente para nossa abordagem crítica e explicativa, no sentido de que para o autor, as identidades se constituem dentro do âmbito cultural, e os processos sociais na contemporaneidade têm fragmentando cada vez mais as "paisagens culturais" nas quais nossas identidades estão inseridas, provocando uma perda de sentido de si, um "duplo deslocamento" ou "descentração do sujeito", reverberando em "crises de identidade".

Tal referência é pertinente para pensarmos essas tentativas de sutura e homogeneização das identidades docentes, que através de seus corpos, e narrativas, revelam suas crises, suas insuficiências, suas faltas, suas interfaces e seus desacordos com o que chamam de "estrutura" ou "sistema educacional", assim como, revela o grande faz de contas dos "atos de pertença" que não são incorporados, mas ainda assim, impostos pelas lógicas de educação hegemônicas aos sujeitos docentes que ensinam/aprendem.

Faria e Souza (2011, p. 36), apontam que Ciampa (1987) por sua vez, concebe a identidade como metamorfose, em constante transformação, sendo o resultado provisório da intersecção entre a história do sujeito, seu contexto histórico e social e seus projetos, a autora e o autor inferem a partir de Ciampa que:

A identidade tem caráter dinâmico e seu movimento pressupõe uma personagem. A personagem, que, para o autor, é a vivência pessoal de um papel previamente padronizado pela cultura, é fundamental na construção identitária: representa-se a identidade de alguém pela reificação da sua atividade em uma personagem que, por fim, acaba sendo independente da atividade. As diferentes maneiras de se estruturar as personagens resultam diferentes modos de produção identitária. Portanto, identidade é a articulação entre igualdade e diferença. [...] Identidade é movimento, porém, uma vez que a identidade pressuposta é reposta pelos ritos sociais, passa a ser vista como algo dado e não como se dando. (FARIA; SOUZA, 2011, p. 36).

Neste sentido, elucidamos dois pontos. O primeiro, é que nos alinhamos com Hall (2004), quando por meio de uma "nova política da diferença" aponta para a precariedade de qualquer identidade. O segundo é que a abordagem de Ciampa (1987), já anuncia a performance como ferramenta analítica que revela os limites do que se concebe por "identidade", que, diga-se de 
passagem, pode ser analisada como uma ficção criada por padrões culturais, ou, em termos da Teoria do Discurso, por articulações e discursos hegemônicos.

São esses sentidos hegemônicos e essas fantasias que configuram as práticas educativas em relação ao que é ser professor/a, que sugerimos re(pensar) e apontar suas precariedades. E mais, pensar nessa ficção, é também apontar os limites do que se entende por estrutura educacional e/ou sistema de ensino. Como exemplos dessa ficção, apontamos os diversos adjetivos fictícios/fantasiosos e significantes atribuídos à figura docente, como: "tia"18; "tio"; herói; guerreiro/a; um/a membro/a da segunda família; "como um/a psicólogo para mim”, "o pai e a mãe que eu nunca tive", os quais ouvimos em nossa experiência docente. Tantos estágios curriculares supervisionados na formação universitária ainda não dariam conta da nossa experiência de assumir a sala de aula como corpo dissidente: apenas um souvenir do que estaria por vir. Com a acusação de sermos demasiadamente "diferentes", passamos a criar estratégias - a tal performance - na experiência de ensinar. No entendimento de Paulo Freire (1996) "se estivesse claro para nós que foi aprendendo que percebemos ser possível ensinar, teríamos entendido com facilidade a importância das experiências informais nas ruas, nas praças, no trabalho, nas salas de aula das escolas" (FREIRE, 1996, p. 49). E porque não em Mesas de bares? Em festas? Em raves? Protestos? Ativismos plurais? Esquinas de avenidas? Em religiões para além das cristãs/hegemônicas? Em sinais de trânsito? Fora das igrejas, dos ternos, reuniões formais, instituições tradicionais e lugares sofisticados?

Relacionando o caráter contingencial com as perspectivas sociais que atravessam os corpos docentes, é possível questionar: os/as professores/as são todos/as iguais? Ou modificaram seu perfil de acordo com cada momento histórico? (Re)produzem as lógicas sociais da ficção docente? Possuem as mesmas práticas e identidades?

O que afirmamos e indagamos, pode ser encontrado facilmente no movimento de tensão que Dubar (1977) percebe nos processos de constituição das identidades. Para o autor, nós, enquanto sujeitos, assumimos diversas identidades, que podem ser "identidades para si" (biográfico) e "identidades para o outro" (relacional). O problema consiste em pensar o/a profissional docente a partir de uma lógica identitária sempre voltada ao outro em todas as instâncias, mesmo quando não ocorrem os "atos de pertença"; que seria quando o sujeito aceita e incorpora as identidades recebidas pelo que lhe é externo, através de uma identificação, em termos de socialização.

Se o sujeito está cercado e atravessado de discursos como dispositivos socioculturais que o modelam, até o próprio conceito de identidade pode ser questionado, uma vez que os marcadores sociais (raça, gênero, sexualidade) e as instituições tradicionais (escola, religião, família) foram e continuam sendo desestabilizados através das inúmeras formas de estar no mundo e dos demais espaços do mundo da vida. Desta forma, os/as docentes produzem performatividades corporais que transitam entre esses marcadores identitários. Pensando os corpos docentes através da concepção de performatividade em Butler, Caetano (2016) nos alerta que:

[...] os suportes identitários migram de um círculo social para outros círculos, constituindo inúmeras figuras e configurações. [...]. Ao performatizar a identidade que me é solicitada para um espaço não significa que estou eliminando de mim as experiências que vivenciei em outros espaços com outras identidades. O corpo suporta as experiências acumuladas pelas inúmeras identidades que o formam. Ele é a performatividade subjetiva e social dos arranjos da personagem que o sujeito interpreta. O sujeito é uma personagem. Nesse entendimento reside

${ }^{18}$ Para saber mais, ver "Professora sim, tia não: Cartas a quem ousa ensinar" de Paulo Freire (1997). 
a singularidade performativa do sujeito, ainda que verbalizada e compartilhada com outros (CAETANO, 2016, p. 59).

Desse modo, performance se associa à "contingência radical" (BUTLER, 2013), compreendida como constitutiva dos corpos docentes inseridos em espaços discursivos que se associam e se disputam por meio de uma relação interdiscursiva de "concorrência". Neste sentido reiteramos a concepção de que corpos são discursivos por produzir performances. Tais embates reverberam também nos movimentos curriculares das instituições escolares onde estão inseridos corpos também dissidentes que convergem e divergem dentro desses espaços de interdiscursividade: corpos negros; corpos indígenas; corpos gordos; professoras lésbicas; professores gays; bissexuais e transgêneros; não-binários; feministas; anti-proibicionistas; afroindígenas religiosos; surdos/as; homens como educadores da educação infantil, docentes provenientes de movimentos sociais, corpos tatuados e/ou com mudanças corporais dissidentes, professoras-mulheres de ciências exatas, docentes que abordam os temas "polêmicos" e "tabus" nas esferas políticas e sociais como gênero e orientação sexual; professores/as atores e atrizes, profissionais do sexo, pessoas com deficiência (PCD); entre outros corpos que estão na escola desafiando - como as nossas narrativas - os processos hegemônicos normatizadores do "ser docente".

\section{PERFORMANCES HEGEMÔNICAS E CORPOS DOCENTES/DISSIDENTES: EXPLICANDO A FICÇÃO A PARTIR DA (IM)POSSIBILIDADE DO SUJEITO}

Nas décadas de 1980 e 1990, surge uma figura incomum na cena LGBTQI+ carioca: Laura de Vison (1939-2007), denominada como transformista (termo antigo para drag queen/king), ficou famosa por seus espetáculos no Cabaré Boêmio, considerados um dos primeiros espaços de encontro da comunidade de homens homossexuais da classe trabalhadora do Rio de Janeiro. Conforme Rodrigues (2014) era conhecida por reunir todas as tribos na boêmia - termo similar à vadiagem e à malandragem - foi comparada à Divine, estrela do filme Pink Flamingos (1972) e suas performances ficaram conhecidas pelo seu peculiar escracho, seja quando interpretava Gal Costa de "Vaca Profana" até quando comia carne crua em (ob)cenas consideradas chocantes e repugnantes - inspiradas nos Acionistas Vienenses, artistas de língua alemã dos anos 1960, que misturavam sexo e sangue em suas apresentações - atraindo também grande número de turistas europeus ao Cabaré Boêmio, localizado na mesma rua em que travestis e transexuais se prostituíam.

Laura de Vison lançou diversos personagens transformistas na época (Rose Bombom e Suzy Brasil, por exemplo) e vivenciou a geração ameaçada pela epidemia da AIDS e pela ditadura militar no Brasil, sendo uma das poucas artistas a continuar trabalhando e trazendo alegria em tempos que precisavam de esperança para (sobre)viver. Mas o que realmente chama atenção na vida de Laura para este trabalho é sua suposta "dualidade" moral: em visita ao Brasil, o famoso estilista Jean Paul Gaultier chegou a ver seus shows e ficou impressionado com seu trabalho de professor de História de dia e drag queen à noite.

A concepção do sujeito pós-moderno em Hall (2004), pode ser um ponto de partida para pensarmos a desestruturação da prática docente, tal concepção, também se aproxima da concepção de sujeito em Laclau e Mouffe (2015), como veremos a seguir. Em tal abordagem, Hall descarta a fixação do sujeito, assim como seu essencialismo e permanência. Quando vemos a história de Laura com o pensamento de que "um professor que não deveria agir assim", nos perguntamos a qual espécie de identidade fixa, acabada, e supra-humana, tal indivíduo se refere. É por não poder "agir assim", que muitos/as professore/as tem ido de encontro aos seus próprios "atos de pertença", 
para performar uma identidade imposta por uma moralidade histórica/contingente que, para além das "estruturas" educacionais, se encontram presentes nos espaços discursivos religiosos e políticoeducacionais, por exemplo.

Abordamos a abertura do sujeito proposta por Hall (2004), não como uma mera perturbação oriunda de ausência de estrutura, pelo contrário, vemos essa abertura como evidência da precariedade, contingência, limites e interdiscursividade de qualquer formação discursiva, inclusive as que difundem - sem medo de deixar escapar sua ignorância e despautério - a crença de que existe "o modelo ideal de educação" ou "o modelo ideal de professor/a" para o mundo, como se o próprio "mundo da vida" não fosse complexo o suficiente e coubesse dentro de estruturas físicas como as escolas onde, analisando-as podemos facilmente fazer analogias entre salas de aulas e gaiolas e entre aulas e fábricas de pensamentos mercantis.

Laura de Vison, nome artístico do professor Norberto Chucri David, desestabiliza as narrativas normatizadas sobre a docência como performance dissidente: um corpo gordo, uma drag queen que discutia e desafiava questões sociais e políticas, inclusive em sala de aula, pensando em seu papel como artista e como professor na produção de contingência de formas de pensar e de agir em meio à repressão existente. Como corpo dissidente, chegou a ser demitido como professor por falar abertamente sobre a AIDS em sala de aula e também foi preso durante o período mais autoritário da ditadura militar no Brasil, logo após o estabelecimento do Ato Institucional número 5 (AI-5), que interditou os direitos políticos através de forte censura e executou prisões sem mandados judiciais.

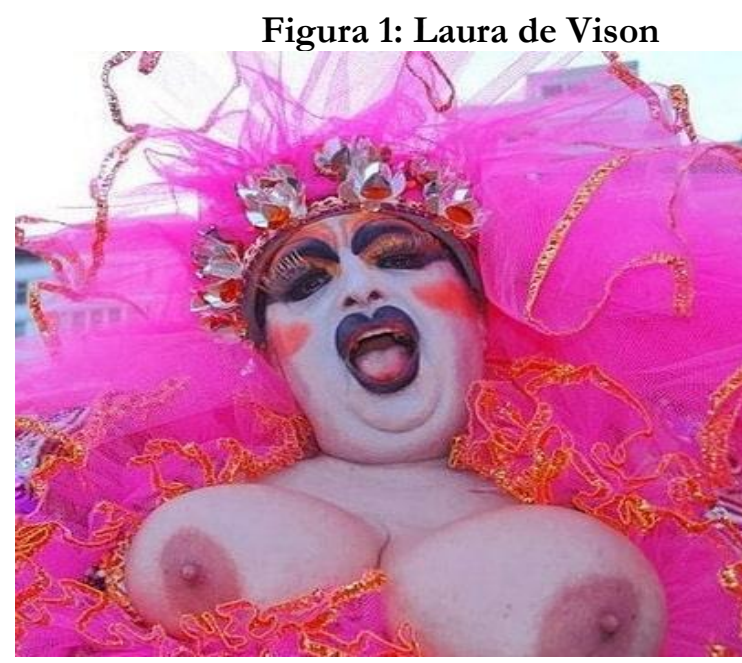

Figura 2: Professor Noberto Chucri

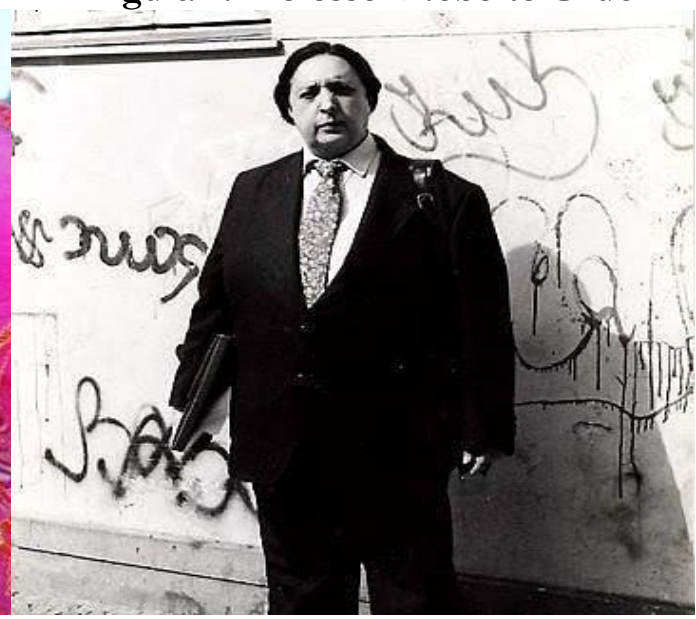

Fonte: http://www.famososquepartiram.com/2012/09/laura-de-vison.html. Acesso em: 23/07/2020.

A história de Laura à noite e Norberto pela manhã, se repete nos dias atuais, nas múltiplas experiências vivenciadas por docentes dissidentes, onde as diversas posições de sujeito são negligenciadas. Segundo Laclau e Mouffe (2015) o racionalismo e empiricismo impõem um papel "constitutivo" de sujeito aos indivíduos humanos, o que contribui, ao nosso entendimento com uma ideia do que o autor e a autora chamam de "sujeito racional e autotransparente". Através dos/a autores, empreendemos que tais implicações estão diretamente relacionadas com uma suposta unidade e homogeneidade do conjunto de posições desses sujeitos.

Tratando este trabalho também como um discurso, nos contrapomos a uma ideia de sujeito docente unificado, originário, que deve ser uma coisa ou outra, determinado por uma ideia de 
externalidade de si mesmo/a. Referimo-nos aqui ao/à docente como um sujeito que reflete várias posições, sendo muitas delas, disputadas por discursos hegemônicos e reacionários.

As experiências vividas antes e durante o processo de ser e/ou tornar-se professor/a são de extrema importância para refletir as condições discursivas que vão possibilitar profissionais que lecionam ou irão lecionar de responderem a si mesmos/as: que tipo de docente sou eu? O que eu preciso para este ofício? Falamos de professores/as que erram; que se equivocam; que são imperfeitos/as; que desistem por um dia e depois voltam atrás; que sentem medo; que às vezes se excedem; que saem da sala de aula e vão chorar no banheiro da escola; que às vezes são mais infantis e despreparados/as que seus próprios alunos/as; que não só amam, mas também odeiam a educação; que têm por escolha, ou não, uma vida totalmente oposta ao que se espera tradicionalmente de um/a professor/a. Acreditamos que a existência desses sujeitos por si só já é transformadora e que aceitar este cenário, antes de tudo, é apontar os escombros da educação falida sob a qual atuamos e somos impedidos/as de agir sobre ela. Antes de ler qualquer manual de emancipação de educação precisamos garantir o direito de ler e analisar nossas próprias práticas e corpos inseridos nestes contextos.

Isso a nosso ver é levar às últimas instâncias o caráter discursivo de todas as posições de sujeito. Reiteramos que "como toda posição de sujeito é uma posição discursiva, ela compartilha do caráter aberto de todo discurso, consequentemente as várias posições não podem ser totalmente fixadas num sistema fechado de diferenças." (LACLAU E MOUFFE, 2015, p. 190-191). Mais que isso, reiteramos que o ofício docente jamais deve ser posto como sobredeterminado às outras posições de sujeito, isso seria um essencialismo que nega não só o caráter contingente dessa noção unificada de sujeito, mas a própria contingência do social e a precariedade de qualquer identidade. Assim como Laclau e Mouffe (2015) também alertamos para a concepção de que toda relação de representação é fundada em uma ficção, ficção esta que têm permanecido presente nas fantasias sociais sobre o ser professor/a.

Muitos/as estudantes de licenciatura incorporam esse ethos docente/hegemônico, sem se quer repensar sobre a necessidade dessa identidade fechada, concreta e absoluta. Isso se dá porque aprendemos a ensinar de forma instrumentalizada e não crítica e porque nós professores/as, muitas vezes não aprendemos a pensar, apenas a (re)produzir conteúdos. Nesse sentido de re(produção), $\mathrm{o} / \mathrm{a}$ docente em formação corresponde não a um/a agente educacional, mas a uma performatividade regulada que reage aos interesses das forças discursivas operantes sobre os sistemas educacionais e dessa forma, os interesses educacionais não são construídos pelas "autonomias" de práticas docentes, pois os sujeitos estão sendo interpelados pelas demandas dos discursos que por hora são hegemônicos.

\section{CONCLUSÃO}

A representação de uma identidade docente não está dada, ela se constrói aqui e agora, dentro e fora da norma, dentro e fora do que é determinado e aceito pela moralidade e discursos hegemônicos. Ser um professor/a dissidente significa romper com a universalidade, angelicalização, padrões sociais pré-estabelecidos, desvios de funções, higienização e totalização das práticas educacionais. A história da educação no Brasil denuncia seus escombros, ela foi e permanece sendo tratada como esteira para fins e ordens políticas, e o/a professor/a tem sido o ator/atriz que é formado a interpretar personagens e a resistir ou não, a tais papéis; como quem dribla e se esquiva das regras de um jogo hostil, violento, desumano e sutilmente exploratório. 
Por exemplo, lemos "Pedagogia da autonomia" de Paulo Freire (1996) na graduação como preparação para o que devemos ou não fazer em sala de aula, que atitudes tomar, o que esperar dos/as estudantes, que subjetividade(s) carregar neste corpo que quer agir, transformar, educar, mudar o mundo através da educação. Uma das contribuições deste trabalho é que não há manual, nem literatura, nem formação (inicial ou continuada), nem estágio, nem palestras que deem conta do "fazer" docente, do "chão" da escola. Porém, em defesa de Freire, ao que nos parece, nem este pressupunha (nem pretendia) dar conta de tantas facetas, subjetividades, dicotomias e desafios. Carregando hoje o título de patrono da educação brasileira, este criou seu próprio método de alfabetização e o conceito de educação emancipadora em sua obra como formas de subjetivar coletivamente as experiências político-pedagógicas através de cada contexto, de cada sujeito. Não à toa, assim como Laura de Vison, na época da ditadura militar, Paulo Freire foi exilado e, nos dias atuais (em tempos bolsonaristas), sua carreira enquanto docente, assim como as suas obras têm sofrido diversos ataques, tanto pelo mesmo ser considerado um educador "esquerdista", como por sua conduta dissidente e transgressora. Mais do que reiterar a distância entre teoria e prática, entendemos que nenhuma obra seria capaz de assumir uma "receita de bolo" para lecionar, só o ponto de partida: seria função de nossa própria performance ressignificar, quaisquer literatura acadêmica que tem a pretensão de discutir o "fazer" docente de forma fechada e totalizante, que revira e desestabiliza nossos corpos em busca de uma pedagogia do eu.

Esse trabalho foi feito por docentes e para docentes; considerando-nos igualmente como corpos docentes diversos, corpos no (e para) o mundo, como olhos que enxergam as discrepâncias nas instituições que lecionamos; como ouvidos que escutam repreensões e reclamações por serem a "tia" e o "tio" diferente; como bocas que se queixam nos conselhos de classe e nas avaliações institucionais; como mãos que tocam e cuidam; pés que correm; coxas que roçam; sentidos de genitálias que incomodam; corpos que movimentam o currículo para ensinar e aprender com discentes que similarmente ensinam. Quem vai "ensinar" esse corpo a ensinar? A como ensinar? O que ensinar? As discussões trazidas neste trabalho não dão conta desse(s) corpo(s), de sua(s) prática(s) e de suas angústias, mas denuncia as fantasias que segmentam, e as ficções que adoecem, marginalizam e estigmatizam não só os/as professores/as, mas aqueles/aquelas que ainda são tratados como sujeitos sem luz (alunos/as).

Vivenciamos tempos sombrios e desafiadores que reiteram e pretendem perpetuar esse status quo: o fascismo à la brasileira de Bolsonaro ameaça usurpar o direito à educação e o direito à diferença, que coíbem a performance docente dissidente, nos exigindo ainda mais do que já estamos acostumadas/os a resistir. O bolsonarismo - sustentado pelo capitalismo neoliberal, pelo patriarcado, pelo racismo estrutural, pelas religiões ultraconservadoras e por outros sistemas repressores que o sustentam até hoje - decidiu barbarizar a educação, decidiu nos adoecer, algemar, exilar, tirar nossos empregos, impelir nossa prática pedagógica, enfim, nos desumanizar.

Mas nós decidimos viver (mais do que sobreviver), decidimos resistir: a presença desses corpos dissidentes nos espaços educacionais criam novas possibilidades discursivas que constituem a(s) realidade(s), que fazem fissuras nesses sistemas, nesses currículos. Os movimentos sindicalistas de professores/as; a instituição do piso salarial; a Campanha Nacional pelo Direito à Educação; as ocupações das escolas estaduais e das universidades; a greve nacional da educação de 2019; a decisão da inconstitucionalidade do movimento "Escola sem Partido" e da proibição da "ideologia de gênero"; são experiências que atravessam e desestabilizam os discursos ultraconservadores, abrem caminhos para pensar a educação democrática e a liberdade de ensinar e de "ser" docente. bell hooks (2013) (nome em minúsculo pois é assim que a autora prefere ser citada) em sua obra "ensinar a transgredir" nos convida a pensar sobre a seguinte provocação: talvez o que ensine a 
ensinar se constitua pelo amor - não o amor romantizado e despolitizado, da "tia" condescendente - mas o amor pelo debate e inquietação do que seria "ética", pela nossa autoestima e autocuidado, por educar como recurso para o enfrentamento político, o que nos conduz para o desmanche e transformação do modelo educacional (re)produtor das desigualdades e fixações. Educar é um ato político de transgressão, e os nossos discursos e corpos "se fazem e refazem" nas práticas pedagógicas.

\section{REFERÊNCIAS}

ANDRÉ, Merli. A produção acadêmica sobre formação de professores: um estudo comparativo das dissertações e teses defendidas nos anos de 1990 e 2000. Formação docente - Revista Brasileira de formação de professores, v. 01, n. 01, p. 41-56, ago./dez. 2009.

ARRUZA, Cinzia; BHATTACHARYA, Tithi; FRASER, Nancy. Feminismo para os 99\% um manifesto. São Paulo: Boitempo, 2019.

BAUMAN, Zygmunt. Identidade: entrevista a Benedetto Vecchi. Rio de Janeiro: Jorge Zahar, 2005.

BBC NEWS. Em gráfico, os 10 países do mundo com mais mortes per capita por covid-19. Disponível em: https://www.bbc.com/portuguese/geral-

54390838\#: :text=Os\%20Estados $\% 20$ Unidos $\% 20$ estariam $\% 20$ no, $\%$ \%20e $\% 20 \operatorname{Ir} \%$ C $3 \%$ A3 $\% 20(2$ 6.567). Acesso em: 21 outubro 2020.

BEAUVOIR, Simone de. O segundo sexo: a experiência vivida. São Paulo: Difusão Européia do Livro, 1967.

BUTLER, Judith. Problemas de gênero: feminismo e subversão da identidade. Rio de Janeiro: Civilização Brasileira, 2003.

CAETANO, Márcio. Performatividades reguladas: heteronormatividade, narrativas bibliográficas e educação. Curitiba: Appris, 2016.

CÁSSIO, Fernando (org). A educação contra a barbárie: por escolas democráticas e pela liberdade de ensinar. São Paulo: Boitempo, 2019.

CIAMPA, Antônio da Costa. A estória do Severino e a história da Severina. São Paulo: Editora Brasiliense, 1987.

FOUCAULT, Michel. Vigiar e Punir: história da violência nas prisões. Petrópolis: Editora Vozes, 1987. FREIRE, Paulo. Pedagogia da autonomia: saberes necessários à prática educativa. Rio de Janeiro: Paz e Terra, 1996.

FREIRE, Paulo. Professora sim, tia não: Cartas a quem ousa ensinar. São Paulo: Olho d'água, 1997.

GLYNOS, Jason; HOWARTH, David. Logics of critical explanation in social and political theory. London/New York: Routledge, 2007.

GLYNOS, Jason; HOWARTH, David. Explicação críticas em ciências sociais: a abordagem das lógicas. In: LOPES, Alice Cassimiro; OLIVEIRA, Ana Luiza Ramos Martins de; OLIVEIRA, Gustavo Gilson Souza de. A teoria do discurso na pesquisa em educação. Recife: Editora UFPE, 2018. p. 53-102.

HALL, Stuart. A identidade cultural na pós-modernidade. Rio de Janeiro: DP\&A, 2004.

hooks, bell. Ensinando a transgredir: a educaşão como prática da liberdade. WMF - Martins Fontes, 2013.

LACLAU, Ernesto e MOUFFE, Chantal. Hegemonia e estratégia socialista. São Paulo: Intermeios, 2015.

LEVY, Gisele Cristina Tenório de Machado; SOBRINHO, Francisco de Paula Nunes; SOUZA, Carlos Alberto Absalão de. Sindrome de Burnout em professores da rede pública. Produção, v. 19, n. 3, p. 458-465. set./dez. 2009.

MERCER, Kobena. Welcome to the jungle. In: J. Ruttherford (Org.), Identity. Londres: Lowrence and Wishart, 1990. 
OLIVEIRA, Gustavo Gilson de. Provocações para aguçar a imaginação/invenção analítica: aproximações entre a teoria política dos discurso e análise do discurso em educação. In: LOPES, Alice Cassimiro; OLIVEIRA, Ana Luiza Ramos Martins de; OLIVEIRA, Gustavo Gilson Souza de. A teoria do discurso na pesquisa em educaşão. Recife: Editora UFPE, 2018. p. 169-216.

OLIVEIRA, Gilson Gustavo; OLIVEIRA, Luiza Anna; MESQUITA, Rui Gomes de. A Teoria do Discurso de Laclau e Mouffe e a Pesquisa em Educação. Educação \& Realidade, Porto Alegre, v. 38, n. 4, p. 1327-1349, out./dez. 2013.

PAIVA, José Maria de. Educação jesuítica no Brasil Colonial. IN: LOPES, Eliana Marta Teixeira; FARIA FILHO, Luciano Mendes; VEIGA, Cynthia Greive. 500 anos de educaşão no Brasil. Belo Horizonte: Autêntica. 2000.

RÍOS, Marcela Lagarde y de los. La multidimensionalidad de la categoría género y del feminismo. In: MARÍN, María González. Metodología de los estudios de género. México: Unam, IIES, 2004. RODRIGUES, Walace. Brincando com gênero: Laura de Vison, um(a) artista de nossos tempos. In: RISCALORI, Eliseu. (org.) Diversidades - diálogos (im)pertinentes entre educação, literatura e sexualidade. 1. ed. Curitiba, PR: CRV, 2014.

SILVA, Silas Veloso de Paula; ALVES, Isabella Nara Costa; VIDAL, Fernanda Gueiros. "Ideologia de gênero" e Escola Sem Partido: desafios do ensino da Sociologia na política brasileira a partir dos embates hegemônicos em torno da educação. Revista Diversidade e Educação v. 8, n. 1 (2020). Disponível em: https://periodicos.furg.br/divedu/article/view/11393. Acesso em: 10 setembro 2020.

VILLELA, Heloisa de Oliveira. O mestre-escola e a professora. IN: LOPES, Eliana Marta Teixeira; FARIA FILHO, Luciano Mendes; VEIGA, Cynthia Greive. 500 anos de educação no Brasil. Belo Horizonte: Autêntica. 2000.

\section{Informações do(a)(s) autor(a)(es)}

Silas Veloso de Paula Silva

Universidade Federal de Pernambuco

E-mail: silasvelosocontato@outlook.com.br

ORCID: https://orcid.org/0000-0001-7845-3809

Link Lattes: http:// lattes.cnpq.br/4145728692120836

Isabella Nara Costa Alves

Universidade Federal de Pernambuco

E-mail: isabellanarac@gmail.com

ORCID: http://orcid.org/0000-0003-3618-2777

Link Lattes: http:// lattes.cnpq.br/1330270840290441 